Research Article

\title{
Earthquake Influence on the Rail Irregularity on High-Speed Railway Bridge
}

\author{
Zhipeng Lai, Xin Kang, Lizhong Jiang, Wangbao Zhou (D), Yulin Feng, Yuntai Zhang, \\ Jian Yu, and Leixin Nie
}

School of Civil Engineering, Central South University, Changsha, China

Correspondence should be addressed to Wangbao Zhou; zhouwangbao@163.com

Received 23 December 2019; Revised 18 August 2020; Accepted 24 August 2020; Published 18 September 2020

Academic Editor: Mahmoud Bayat

Copyright ( 2020 Zhipeng Lai et al. This is an open access article distributed under the Creative Commons Attribution License, which permits unrestricted use, distribution, and reproduction in any medium, provided the original work is properly cited.

\begin{abstract}
Rail irregularity is the leading cause of enhancing train-track coupling vibration and, therefore, should be studied in detail for safety requirements. In this study, the differences between existing rail irregularities without being subjected to an earthquake between different countries were first studied. Results show that existing power spectrum density and time-domain displacement samples of rail irregularities in the American code are the largest, while the irregularities of the Germany railway are higher than those of China in a specific range of rail wavelengths. Afterward, the effects of earthquake intensity, soil site, and duration on the rail irregularity of a Chinese typical high-speed railway bridge were investigated. For this purpose, a finite element model was established and validated by the shaking table test of a 1/12-scaled high-speed railway bridge experimental specimen. The calculation results indicated that the influences of earthquakes on the rail alignment irregularity were evident.
\end{abstract}

\section{Introduction}

As a directly contacted component with the wheels of a train [1], the rails are usually shown a noticeable randomness irregularity due to the abrasion and damage of long-time usage. Because of this, the rail irregularity [2] affects mostly the stability and safety of trains when it was passing through the track, especially for the train with high speed. Relevant researches $[3,4]$ indicate that rail irregularity is a random function which changes with the mileage of rail. Therefore, for a better understanding of the characteristic of rail irregularity, the power spectrum density (PSD) [5] is mostly used because it illustrates clearly the relationship between the rail wavelength and irregularity magnitude [6]. Relevant studies illustrate that a train is usually excited by four types of rail irregularities (i.e., vertical, alignment, cross, and gauge irregularities), as shown in Figure 1. Except for external excitation (e.g., earthquake and wind load), the rail irregularity is the leading cause of enhancing dynamic responses in the train-track coupling system [7], and its characters should be studied in detail for safety requirements.

For decades, extensive research has been conducted to study rail irregularity. For example, some of the researches
[8-12] investigated the measurement methods to identify different irregularities, while other work $[13,14]$ concentrated on the finite element (FE) modeling to simulate or predict the irregularity. However, little research studied the existing PSD characteristic and time-domain displacement sample of rail irregularities, which are essential for train-track coupling vibration $[15,16]$. Moreover, few of these studies have investigated the difference of irregularity between different countries, such as the USA, Germany, and China, which are the most typical countries that have established rail irregularity PSDs. Therefore, the characteristics of rail irregularity (PSD and displacement excitation sample) in these three countries were studied and compared for a better understanding of the research gap in the first place.

Moreover, with the needs of increasing the train speed, high-speed railways (HSRs) with the ballastless track, as shown in Figure 2, have been widely constructed in the world $[17,18]$. Analytical studies pointed out critical speed existed for the train passing through HSR bridges $[19,20]$. Many types of research studied the influence of irregularity on the train-bridge coupling vibration on an HSR line. Gae et al. [21] established a train-HSR bridge model and studied the sensitivity of rail wavelengths to the dynamic 


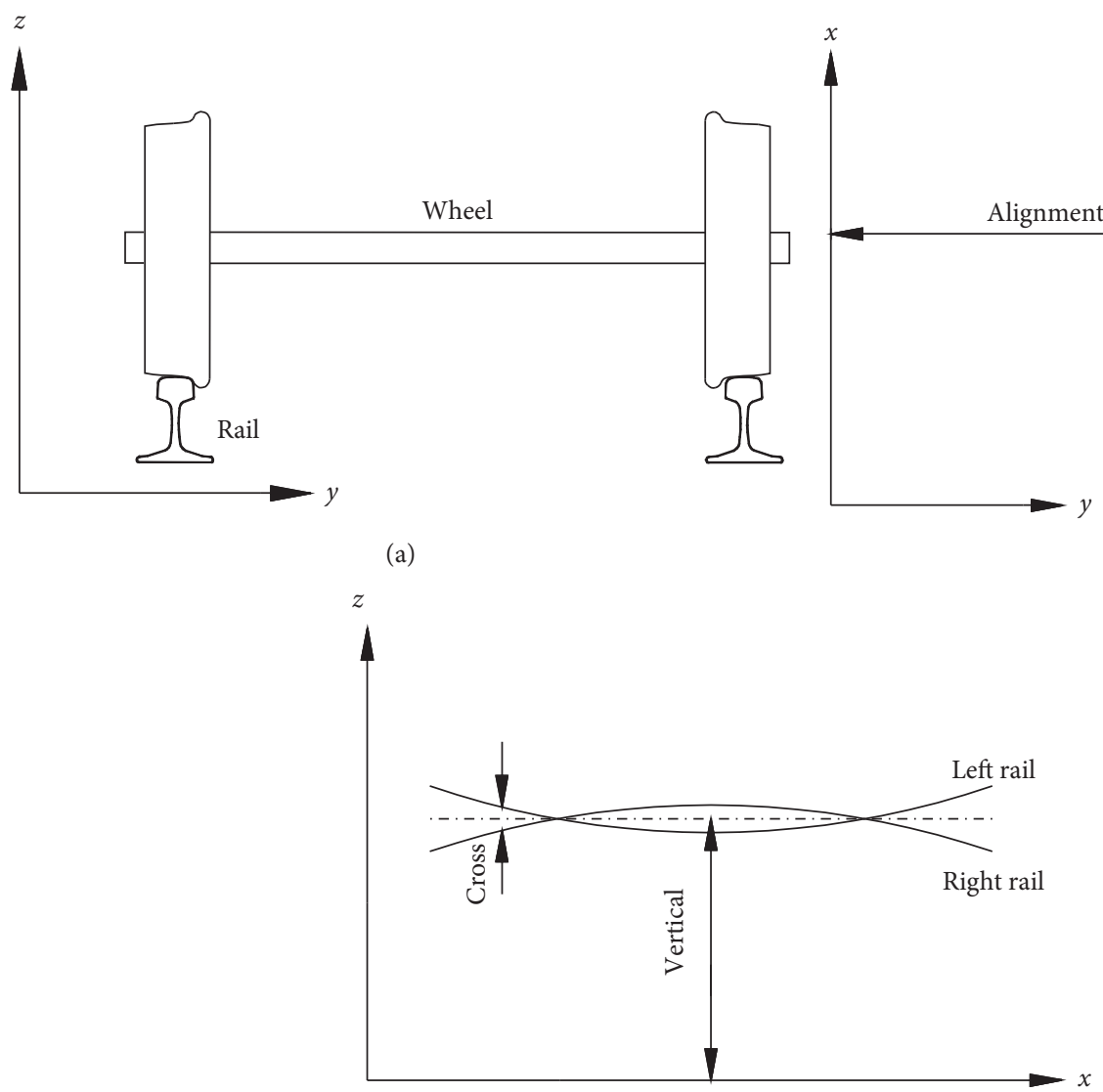

(c)

FIGURE 1: Schematic diagram of wheel-rail contact and rail irregularity types. (a) Wheel-rail contact. (b) Alignment and gauge irregularities. (c) Vertical and cross irregularities.

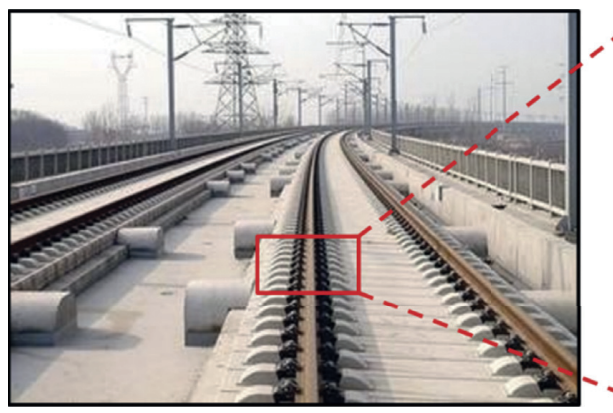

(a)

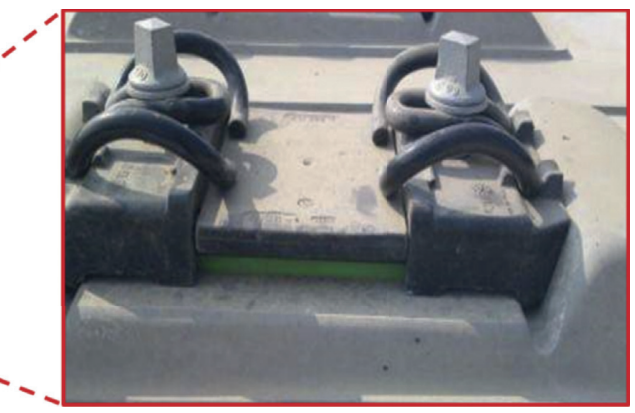

(b)

FIgURE 2: Component in HSR of (a) track system and (b) fasten.

performance of the HSR bridge. Yang et al. [22] developed a vehicle-track interaction model and investigated the effects of irregularity on the dynamic response of the track system on an HSR line. Kargarnovin et al. [23] carried out a parametric study to investigate the influence of irregularity on the ride comfort of high-speed trains passing over railway bridges. Xia and Zhang [24] numerically studied the dynamic behavior of the train-HSR bridge excited by irregularity. Biondi et al. [25] analyzed the influence of vertical irregularity on both train's and bridge's vibrations by a numerical model of train-track-bridge interactions.
In addition, the PSD of rail irregularity on HSRs was studied extensively. Wang and Zhang [26] studied the rail irregularity power spectrum on HSRs and illustrated the maximum irregularity value at different train speeds. Li et al. [27] evaluated the spectrum of track irregularity for the Wuhan-Guangzhou HSR line built in China and obtained a suitable PSD for this railway. However, few studies have concerned the effects of the earthquake on the change of irregularity on HSR, which can generate additional threats to the safety of passing train. For example, unrecoverable displacement can be found in the rail as HSR is damaged 
[28], and the initial geometry of the track is changed due to the effects of the earthquakes. Therefore, the original existing PSD without being subjected to the earthquakes cannot express the track geometry accurately after seismic shaking. The time-domain displacement sample, which is generated from the PSD, will change due to the influence of earthquake. As the second work of this paper, the effects of different intensities and shear velocities of the earthquakes on the rail irregularity are investigated in detail.

Previous researches indicate that the track geometry is essential to the safety of train passing through HSR bridges. Since the HSR bridge and track [29] may be damaged $[30,31]$ subjecting to the seismic shaking, the influences of the earthquake on the change of track irregularities are inevitable and unclear. The major function of the HSR bridge is to keep the safe operation of the high-speed train, and it is critical to find an efficient way to evaluate the damage status of the HSR bridge-track system after the seismic shaking. One critical point of evaluating the functionality of the HSR bridge is to quantify the earthquake-induced track irregularities. However, the existingd international PSDs of rail irregularity only give concern about the initial drawbacks in the railway line, and few relevant works concerned the geometry changes of the track after an earthquake.

In this study, the influences of earthquakes on the rail irregularity on an HSR bridge are major concerns. To get a full understanding of the status of the initial rail irregularity in China's HSR line, the characteristic of existing rail irregularities without being subjected to the earthquakes in different central countries are compared and discussed firstly. Subsequently, a refined finite element (FE) HSRB model, which includes the pier, girder, track, rail, and relevant connecting components (i.e., bearing, fasten, CA layer, and slide layer), is established and validated by a shaking table test of $1 / 12$-scaled HSRB specimen. Therefore, the residual rail displacements after being subjected to different earthquake excitations can be calculated by this validated FE model. Then, the time-domain displacement samples of existing rail irregularities without being subjected to earthquakes are generated by the PSD of rail irregularity. Finally, the earthquake-influenced time-domain displacement samples are obtained by adding the residual rail displacements and existing irregularity displacement samples. After applying inverse fast Fourier transformation (IFFT) to these calculated time-domain displacement samples, the earthquake-influenced rail irregularity PSDs are obtained. The influence of different earthquake intensities and velocities on the irregular PSDs and time-domain displacement samples for a typical Chinese HSRB is studied. The results can be used for future more detailed research; for example, the safety and coupling dynamic analysis of high-speed trains passing through the earthquake-damaged HSRB.

\section{Characteristics of Rail Irregularity in Different Countries}

The existing expression of irregularity without the influence of earthquakes in different countries, such as America, Germany, and China, is firstly described in this section. Then, the power spectrum densities (PSDs) are compared and discussed, which should be found useful by researchers to understand the difference of characteristics in rail irregularity between these countries. Finally, the time-domain displacement sample of rail irregularities in these countries is obtained, and the results can be applied in actual application for better studying the train-rail coupling vibration.

2.1. Brief Description of PSD. The rail irregularities are generally handled according to a stationary random process. Let the rail irregularity sample be $\eta(x)$, and the length of it is $X$; then the definition of a power spectrum density is as follows:

$$
\begin{aligned}
S(f) & =\lim _{\Delta f \longrightarrow 0} \frac{\widehat{\psi}_{\eta}^{2}(f, \Delta f)}{\Delta f} \\
& =\lim _{\Delta f \longrightarrow 0} \frac{1}{\Delta f}\left[\lim _{X \longrightarrow \infty} \frac{1}{X} \int_{0}^{X} \eta^{2}(x, f, \Delta f) \mathrm{d} x\right],
\end{aligned}
$$

where $f$ is the spatial frequency, $\eta(x, f, \Delta f)$ denotes the value when the rail irregularity sample, $\eta(x)$ takes the frequency range of $(f, f+\Delta f)$, and $\widehat{\psi}_{\eta}^{2}(f, \Delta f)$ is the mean square of $\eta(x)$. Since the rail irregularity samples are discrete datum, the PSD is generally obtained using the fast Fourier transform method.

2.1.1. America. Based on a large number of field measurement datum, the Federal Railroad Administration (FRA) in America has measured its own specific rail irregularity PSD, which can be expressed by an even-order function [32]. To be specific, the four types of rail irregularity PSDs are shown in equations (2) to (5):

(a) Vertical irregularity:

$$
S_{v}(\varphi)=\frac{A_{v} \varphi_{v 2}^{2}\left(\varphi^{2}+\varphi_{v 1}^{2}\right)}{\varphi^{4}\left(\varphi^{2}+\varphi_{v 2}^{2}\right)} .
$$

(b) Alignment irregularity:

$$
S_{a}(\varphi)=\frac{A_{a} \varphi_{a 2}^{2}\left(\varphi^{2}+\varphi_{a 1}^{2}\right)}{\varphi^{4}\left(\varphi^{2}+\varphi_{a 2}^{2}\right)} .
$$

(c) Cross irregularity:

$$
S_{c}(\varphi)=\frac{A_{c} \varphi_{c 2}^{2}}{\left(\varphi^{2}+\varphi_{c 1}^{2}\right)\left(\varphi^{2}+\varphi_{c 2}^{2}\right)} .
$$

(d) Gauge irregularity:

$$
S_{g}(\varphi)=\frac{A_{g} \varphi_{g 2}^{2}}{\left(\varphi^{2}+\varphi_{g 1}^{2}\right)\left(\varphi^{2}+\varphi_{g 2}^{2}\right)},
$$

where $S(\varphi)$ is the rail irregularity PSD $\left(\mathrm{m}^{2} /(1 / \mathrm{m})\right), \varphi$ is the sampling space-frequency of rail $(1 / \mathrm{m}), A$ is the roughness constant, and $\varphi_{1}$ and $\varphi_{2}$ are the cutoff space-frequencies. There are six levels for each type of irregularity according to different traffic safety standards and permissible speed. As 
the maximum speed of train for America irregularity is just $176 \mathrm{~km} / \mathrm{h}$, the rails are not suitable for a high-speed train and, therefore, the rails need to be improved for the train passing at a higher speed.

2.1.2. Germany. Unlike the irregularity in America, Germany has developed two different levels (low and high interference, respectively) of PSDs for different train speeds. To be specific, the low interference PSD is used for the train speed exceeding $250 \mathrm{~km} / \mathrm{h}(\geq 250 \mathrm{~km} / \mathrm{h})$, while the high interference is applied for the speed below $250 \mathrm{~km} / \mathrm{h}$ $(<250 \mathrm{~km} / \mathrm{h})$. The expressions of PSD for four types of irregularities in Germany are shown in equations (6) to (9):

(a) Vertical irregularity:

$$
S_{v}(\Omega)=\frac{A_{v} \Omega_{c}^{2}}{\left(\Omega^{2}+\Omega_{r}^{2}\right)\left(\Omega^{2}+\Omega_{c}^{2}\right)} .
$$

(b) Alignment irregularity:

$$
S_{a}(\Omega)=\frac{A_{a} \Omega_{c}^{2}}{\left(\Omega^{2}+\Omega_{r}^{2}\right)\left(\Omega^{2}+\Omega_{c}^{2}\right)} .
$$

(c) Cross irregularity:

$$
S_{c}(\Omega)=\frac{A_{v} b^{-2} \Omega_{c}^{2} \Omega^{2}}{\left(\Omega^{2}+\Omega_{r}^{2}\right)\left(\Omega^{2}+\Omega_{c}^{2}\right)\left(\Omega^{2}+\Omega_{s}^{2}\right)} .
$$

(d) Gauge irregularity:

$$
S_{g}(\Omega)=\frac{A_{g} \Omega_{c}^{2} \Omega^{2}}{\left(\Omega^{2}+\Omega_{r}^{2}\right)\left(\Omega^{2}+\Omega_{c}^{2}\right)\left(\Omega^{2}+\Omega_{s}^{2}\right)},
$$

where $S(\Omega)$ is the PSD of rail irregularity $\left(\mathrm{m}^{2} /(\mathrm{rad} / \mathrm{m})\right), \Omega$ is the sampling space-frequency $(\mathrm{rad} / \mathrm{m})$, while $\Omega_{c}, \Omega_{r}$, and $\Omega_{s}$ refer to the cutoff space-frequencies $(\mathrm{rad} / \mathrm{m})$, and $A_{v}, A_{g}$, and $A_{a}$ are the roughness constants $\left(\mathrm{m}^{2} \times \mathrm{rad} / \mathrm{m}\right)$.

2.1.3. China. As for China, HSRB with ballastless track has been mostly applied in the railway line for a high-speed train (300 to $350 \mathrm{~km} / \mathrm{h})$, and the PSD $\left(\mathrm{mm}^{2} /(1 / \mathrm{m})\right)$ of irregularity can be fitted by power function as shown in equation (10) where $f$ is the sampling space-frequency $(1 / \mathrm{m})$ and $A$ and $n$ are fitting factors for all types of irregularities [33]:

$$
S(f)=\frac{A}{f^{n}} \text {. }
$$

2.2. Comparison of PSD. For a better understanding of the difference of irregularity between America, Germany, and China, all types of PSDs (i.e., vertical, alignment, cross, and gauge) are compared and studied in this section. As shown in Figure 3, the comparison results indicate that the PSDs of America (for all types of irregularities) are the highest one for almost all rail sampling frequencies. This reason is that the maximum permissible train speed is only $176 \mathrm{~km} / \mathrm{h}$ in
America, which is not used for the high-speed train. Therefore, the construction and maintenance requirements of rail in America are less, and rail irregularities are relatively more significant. Moreover, results show that the PSD of Germany is higher than that of China in the vertical irregularity (Figure 3(a)), which illustrates that the requirement of vertical irregularity in China is more restricted. However, a reverse trend can be found in gauge irregularity (Figure 3(d)), and this means that Germany cares more about the gauge irregularity excitation to the train. For the alignment and cross irregularities (Figures 3(b) and 3(c)), the difference of PSD between Germany and China depends on the rail sampling frequency.

\subsection{Comparison of Time-Domain Displacement Samples}

2.3.1. Methodology. As for the train-track coupling dynamic analysis, the excitation of rail irregularities to the train usually adopted the time-domain displacement input [34]. Therefore, PSD of the irregularity should be converted to the time-domain displacement samples. An efficient and accurate method was applied to accomplish this transformation [35]. To be specific, as there was a relationship (e.g., $S_{s}$ $(\Phi) \mathrm{d} \Phi=S_{f}(w) \mathrm{d} w$, where $\Phi$ and $w$ are the space- and timefrequencies, respectively) between the PSD in space and time domains, the original rail space-frequency domain of PSD can be converted into the time-frequency domain. Therefore, the time-frequency spectrum of irregularities can then be obtained by using the following equation [36]:

$$
X(k)=N_{r} \exp \left(i \varphi_{n}\right) \sqrt{S_{n}(k \Delta f) \Delta f}, \quad\left(k=0,1, \ldots, \frac{N_{r}}{2}\right),
$$

where $N_{r}$ is the time-domain sampling points, $\varphi_{n}$ is according to the uniform distribution from 0 to $2 \pi, \Delta f$ is the sampling frequency, and $S_{n}$ is the PSD in space-frequency domain expression. After applying the inverse fast Fourier transform (IFFT) to this spectrum $(X(k))$, the time-domain displacement sample of different irregularities can be obtained.

2.3.2. Results. Figure 4 illustrates the comparison of timedomain displacement irregularity samples (vertical, alignment, cross, and gauge) between America, Germany, and China. It can be clearly seen that the displacement of vertical (Figure 4(a)) and alignment irregularities (Figure 4(b)) is more extensive than that of the cross (Figure 4(c)) and gauge (Figure 4(d)) for all countries. This can ascribe to the fact that compared to the gauge (equation (3)) and cross (equation (5)) irregularities, the alignment (equation (2)) and vertical (equation (4)) irregularities are more easily affected by the erosion (or damage) of rails (left and right). Therefore, the stability of trains will be affected more by the alignment and vertical irregularities in these countries, and high-speed train traveling should pay attention to this. Moreover, the results also show that the minimum displacement excitation of rail irregularities can be found in the Chinese HSR lines (with ballastless track system), while the 


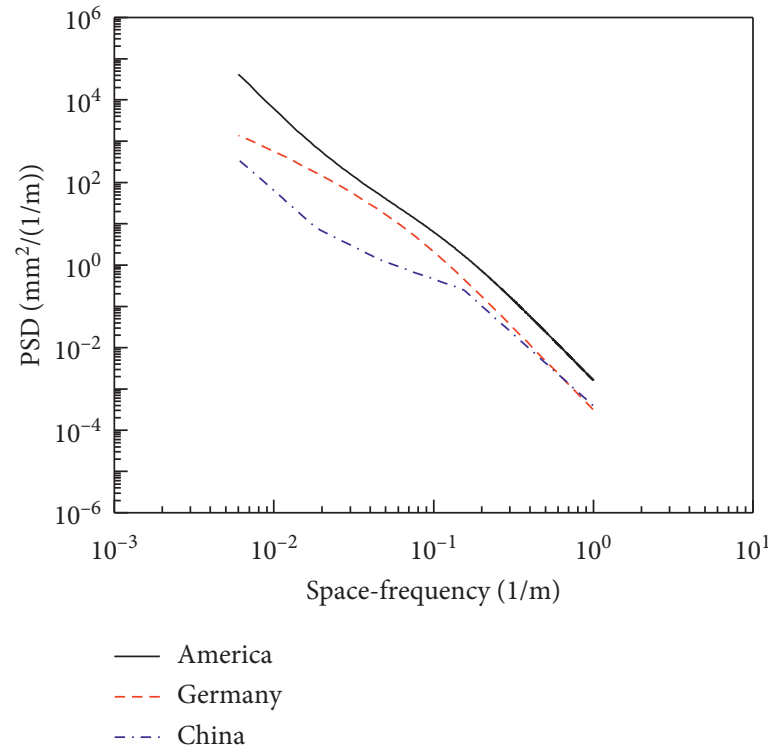

(a)

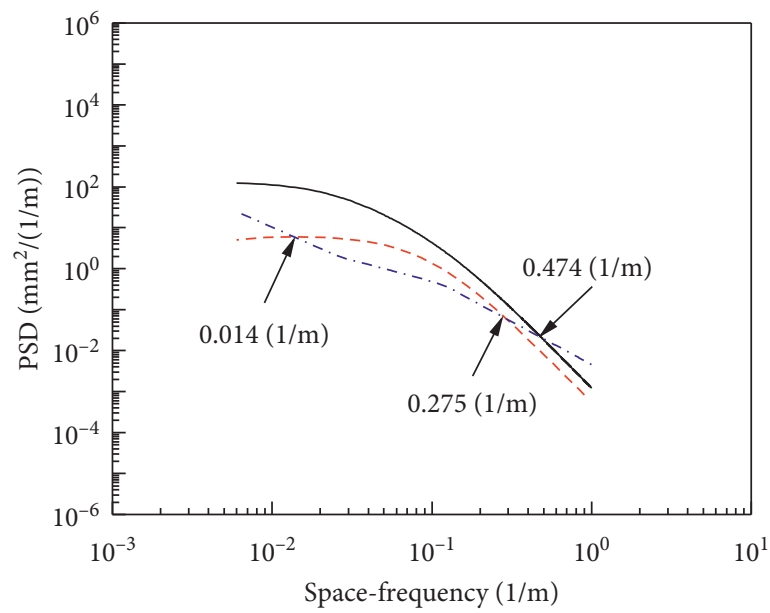

(c)

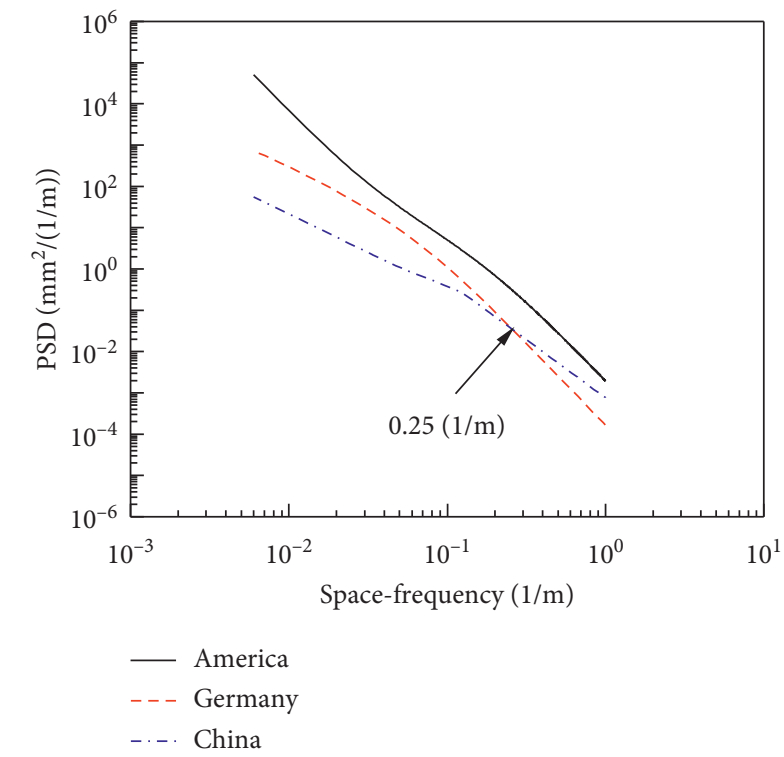

(b)

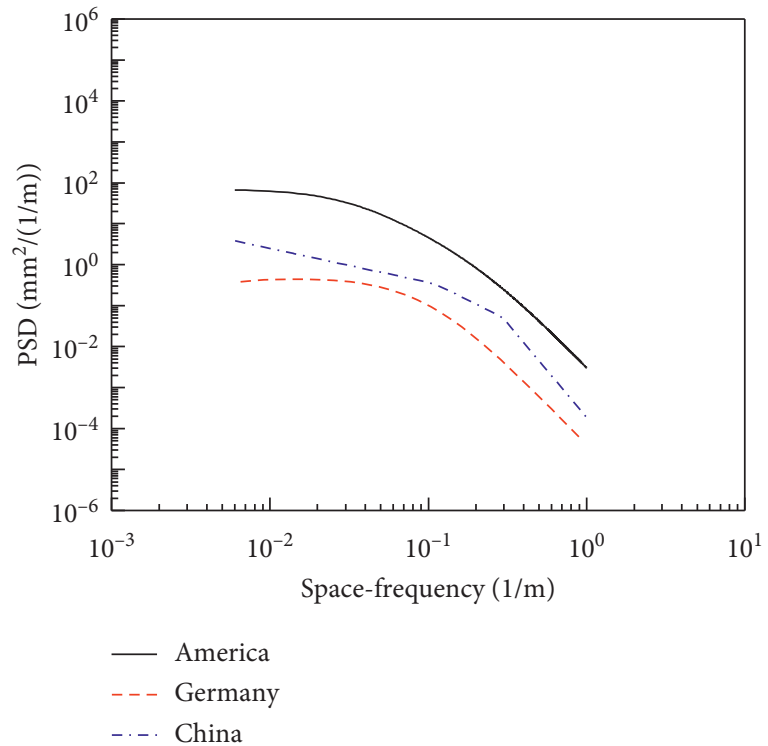

(d)

FIgURE 3: The comparison of PSD for (a) vertical, (b) alignment, (c) cross, and (d) gauge irregularities of rail.

largest one can be seen in America. This is because the Chinese HSR is constructed for high-speed train travel (the maximum operating speed can be $350 \mathrm{~km} / \mathrm{h}$ ), and it has a higher quality of construction (or maintenance). Therefore, the irregularities in Chinese HSR lines are smaller than those of other countries. However, the maximum permissible speed in America is no more than $200 \mathrm{~km} / \mathrm{h}$, and most of the rails have already been used for many years. Thus, it is reasonable that more damage or erosion can be found in America's rail, which results in a higher irregularity displacement sample.

Specifically, the maximum and minimum values of rail irregularity displacement samples in different countries are given in Table 1. It shows clearly that the displacement of vertical and alignment irregularities for America is about $\pm 10 \mathrm{~mm}$, while around $\pm 6 \mathrm{~mm}$ can be found in cross and gauge irregularities. However, as the track systems are both constructed for high-speed trains, the difference of rail irregularity displacements between Germany and China is less noticeable (about $\pm 4 \mathrm{~mm}$ for vertical and alignment irregularities and around $\pm 2 \mathrm{~mm}$ for cross and gauge irregularities). Therefore, the rail-train coupling vibration analysis can find good use of these findings to determine the displacement range of rail excitation to the train.

\section{Shaking Table Test and Finite Element (FE) Modeling}

3.1. Brief Description of the Shaking Table Test. As for the influence of earthquake on the rail irregularity of Chinese 

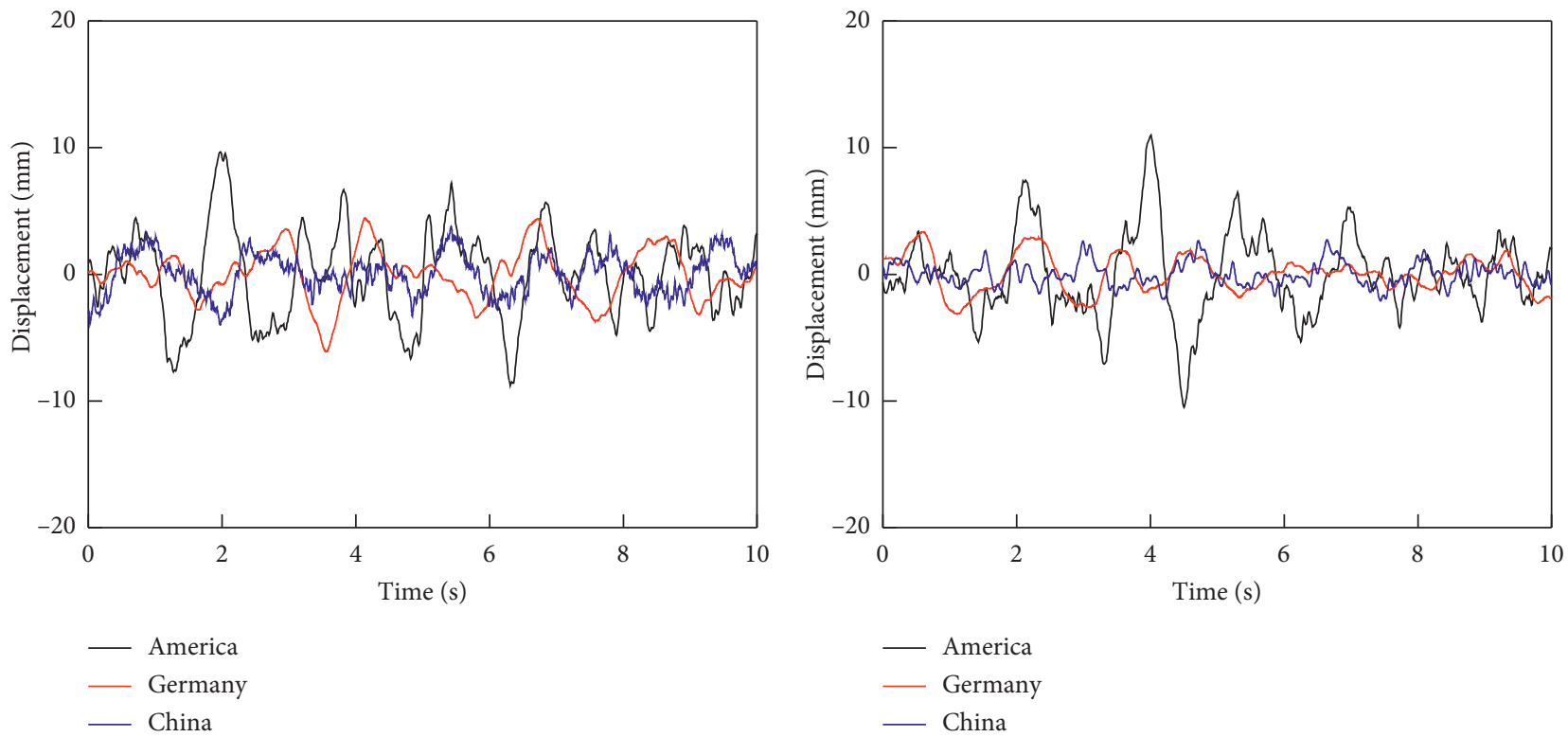

(a)

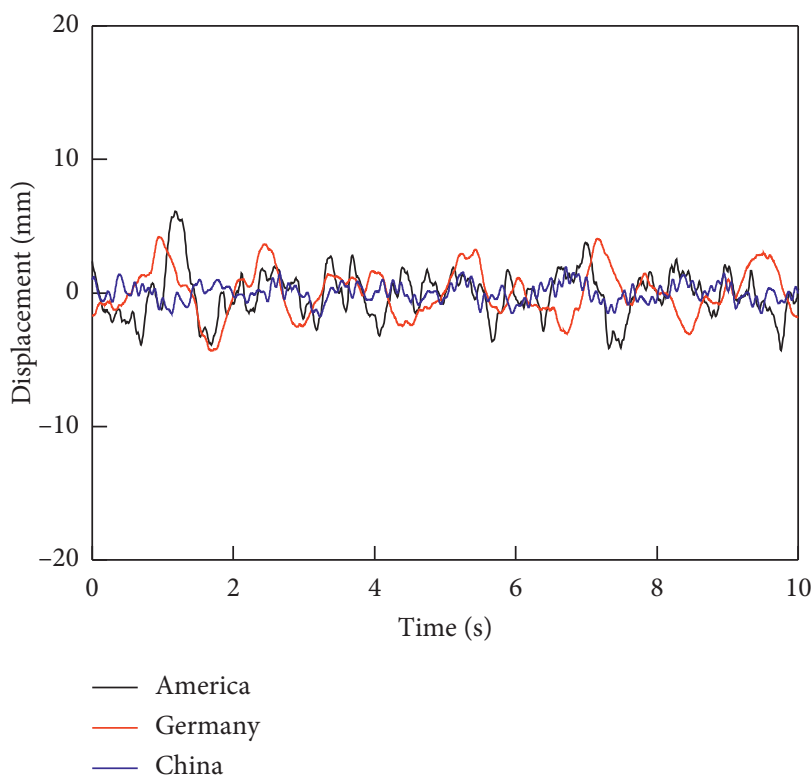

(c)

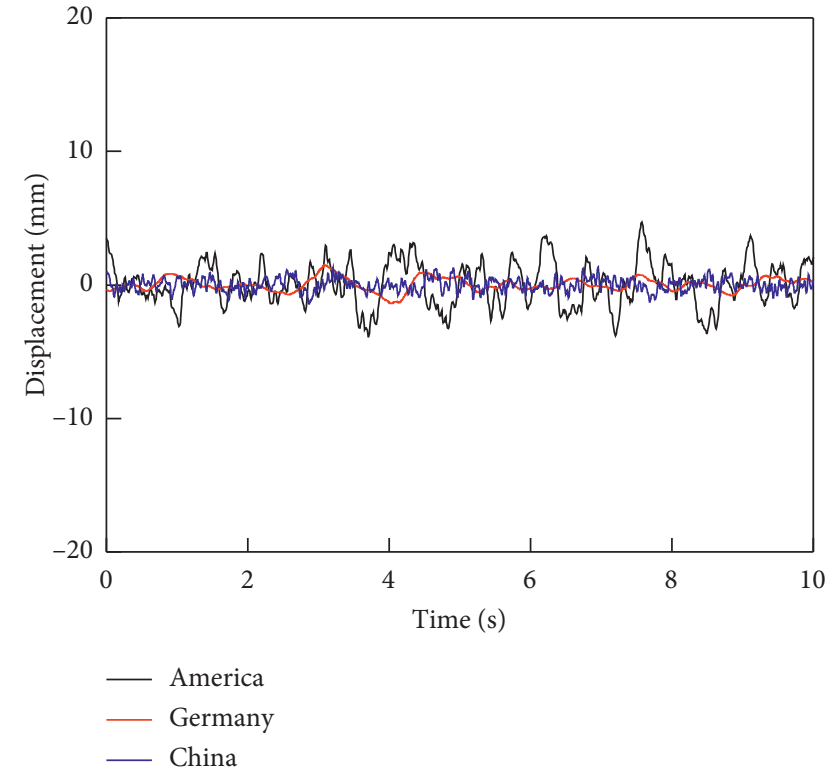

(d)

Figure 4: The comparison of the time-domain sample for (a) vertical, (b) alignment, (c) cross, and (d) gauge rail irregularities.

HSR lines (with ballastless track), a shaking table test of the scaled typical HSR bridge specimen was conducted in the Central South University, China. Moreover, due to the point of this research was to focus on the change of irregularity on the span of a continuous beam bridge, therefore, for better considering the effect of adjacent spans (simply supported bridges) on the seismic performance of the target (continuous) bridge, a multispan HSR bridge was selected. Finally, the actual HSRB was a combination of a simply supported girder and a continuous girder bridge, which was selected from the Beijing-Shanghai HSR line (China). To be specific, the span of the continuous girder bridge was $48+80+48 \mathrm{~m}$ with three spans of simply supported beam bridges ( $32 \mathrm{~m}$ for each span) adjacent to its left and right sides. However, due to the limits of size, acceleration capability, and weighting of shake tables, the geometry and acceleration ratio of the testing bridge specimen was selected at $1 / 12\left(S_{l}=1 / 12\right)$ and $3\left(S_{a}=3\right)$, while the elastic modulus was $1\left(S_{\sigma}=1\right)$ since the same materials are applied in both the experimental specimen and prototype bridges. Other remaining ratios, for example, stress, displacement, and stiffness were determined from these three fundamental ratios using similarity relations, as illustrated in Table 2 [37].

Moreover, concrete block and lead were applied as additional weights to maintain the required density 
TABLE 1: The maximum and minimum displacements of irregularity (unit: $\mathrm{mm}$ ).

\begin{tabular}{|c|c|c|c|c|c|}
\hline Direction & Nation & Speed $(\mathrm{km} / \mathrm{h})$ & Level & Maximum & Minimum \\
\hline \multirow{3}{*}{ Vertical } & America & 100 & 6 & 9.7 & -8.8 \\
\hline & Germany & 350 & Low-interference & 4.4 & -6.1 \\
\hline & China & 350 & High-speed & 3.8 & -4.0 \\
\hline \multirow{3}{*}{ Alignment } & America & 100 & 6 & 10.9 & -10.5 \\
\hline & Germany & 350 & Low-interference & 3.4 & -3.1 \\
\hline & China & 350 & High-speed & 2.7 & -2.1 \\
\hline \multirow{3}{*}{ Cross } & America & 100 & 6 & 6.4 & -5.4 \\
\hline & Germany & 350 & Low-interference & 4.2 & -4.4 \\
\hline & China & 350 & High-speed & 1.9 & -1.8 \\
\hline \multirow{3}{*}{ Gauge } & America & 100 & 6 & 5.5 & -4.7 \\
\hline & Germany & 350 & Low-interference & 1.5 & -1.4 \\
\hline & China & 350 & High-speed & 1.4 & -1.5 \\
\hline
\end{tabular}

TABLe 2: Similitude parameters and similarity ratios of the shaking table test.

\begin{tabular}{|c|c|c|c|}
\hline Property & Physical quantity & Similarity relation & Ratio \\
\hline \multirow{3}{*}{ Material } & Modulus* & $S_{E}$ & 1 \\
\hline & Stress & $S_{\sigma}=S_{E}$ & 1 \\
\hline & Density & $S_{\rho}=S_{\sigma} / S_{a} S_{l}$ & 4 \\
\hline \multirow{3}{*}{ Load } & Point & $S_{P}=S_{E} S_{l}^{2}$ & $1 / 144$ \\
\hline & Line & $S_{\omega}=S_{E} S_{l}$ & $1 / 12$ \\
\hline & Area & $S_{q}=S_{E}$ & 1 \\
\hline \multirow{3}{*}{ Geometric } & Length* & $S_{l}$ & $1 / 12$ \\
\hline & Displacement & $S_{d}=S_{l}$ & $1 / 12$ \\
\hline & Area & $S_{A}=S_{l}^{2}$ & $1 / 144$ \\
\hline \multirow{3}{*}{ Dynamic } & Acceleration* & $S_{a}$ & 3 \\
\hline & Mass & $S_{m}=S_{\rho} S_{l}^{3}$ & $4 / 1728$ \\
\hline & Period & $S_{T}=S_{l}\left(S_{l} S_{E}^{-1}\right)^{0.5}$ & $1 / 6$ \\
\hline
\end{tabular}

${ }^{*}$ Base parameter.

according to similarity $\left(S_{\rho}=4\right.$, Table 2$)$, which uniformly distributed along the deck and pier in this test. Besides, due to the length limit of the shaking table, fixed pot rubber bearings were adopted to approximately simulate the effects of a multispan simply supported beam to the ends of the continuous girder bridge. Also, spherical steel bearings (fixed and movable bearings) were used to support the continuous girder bridge, which was consistent with the actual engineering applications. Finally, the HSRB experimental specimen is assembled, as shown in Figure 5.

Besides, since it is difficult to collect the change of rail irregularity after this HSRB specimen subjected to earthquake excitation, the rail specimen was not constructed on this HSRB specimen, while its scaled mass was taken into consideration in the weighting program according to the similarity relationship (Table 2). Several accelerometers and displacement transducers were installed on the girder and pier to collect their time histories during the shaking table test. Moreover, to easily compare with other similar studies, the El-Centro earthquake wave was used as input excitation in this test. Finally, for simulating the most frequently occurred earthquake intensity in China $(0.20 \mathrm{~g})$, the PGA scale of the experimental earthquake (PGA scale of $0.60 \mathrm{~g}$, shown in Figure 6) was 3 times larger according to the similarity relationships $\left(S_{a}=3\right.$, Table 2$)$.
3.2. FE Modelling and Comparison. The finite element (FE) model of actual HSRB (with the rails) [38] was established with OpenSEES and analyzed in this section. To be specific, as shown in Figure 7, the piers were modeled by nonlinear beam-column elements with fiber sections. Steel 02 and Concrete 02 material were adopted to illustrate the nonlinear mechanical behavior of the steel fiber and concrete fiber, respectively, and the material properties were adopted from the material tests datum. The bridge girder, rails, track slab, and track base were simulated by the elastic beam-column elements. The section constants were generated based on the HSRB prototype. The connection components, such as the bearing, CA mortal layer, slide layer, and rail fastenings, were modeled by elastic-perfectly plastic material. The yielding force and yielding displacement of the elasticperfectly plastic model were denoted as $F_{y}$ and $d_{y}$, respectively. As for the sliding and fixed bearings, $d_{y}$ of them were accepted as $2 \mathrm{~mm}$, while $F_{y}$ of them were accepted as 0.02 and 0.2 times of the vertical reaction forces of bearings. As for the sliding layer in track, $F_{y}$ and $d_{y}$ were $6 \mathrm{kN}$ and $0.5 \mathrm{~mm}$, respectively. As for the CA layer, $F_{y}$ and $d_{y}$ were $41.5 \mathrm{kN}$ and $0.5 \mathrm{~mm}$, respectively.

For better understanding, the details of modeling the upper structure, e.g., the girder, ballastless track system, and connections (CA, slide layer, and fastenings), are shown in Figure 8 . 


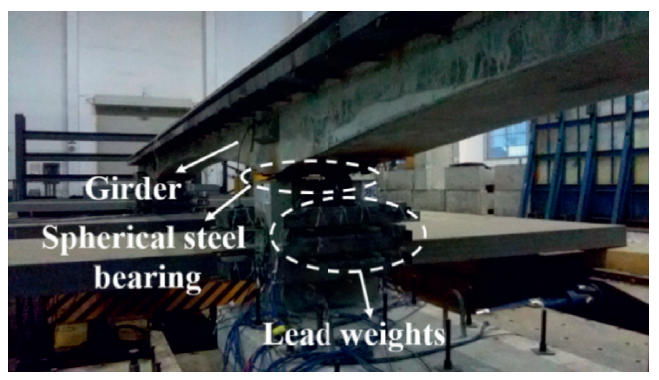

(a)

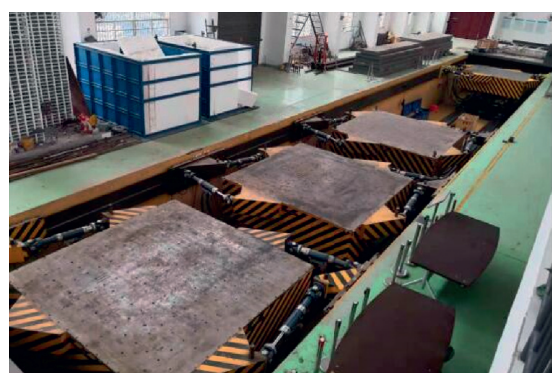

(b)

Figure 5: (a) Assembled HSRB experimental model. (b) Shaking table system.

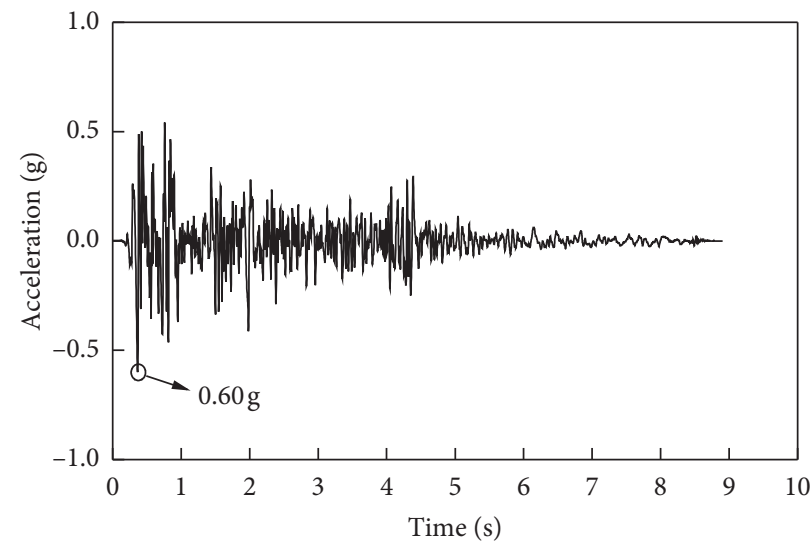

Figure 6: Acceleration-time-history of testing earthquake wave.

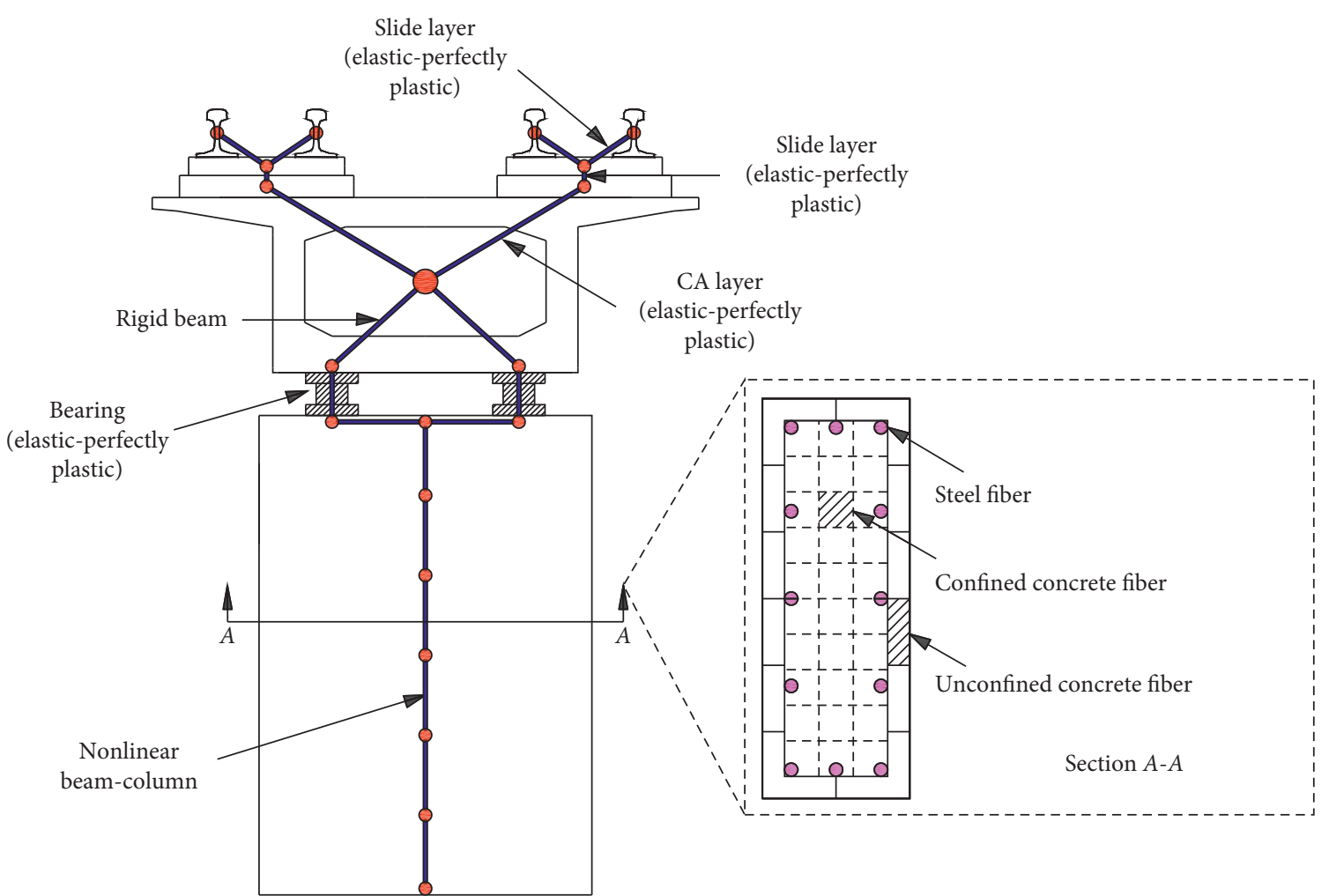

FIgURE 7: Vertical view of modeling scheme for HSRB prototype. 


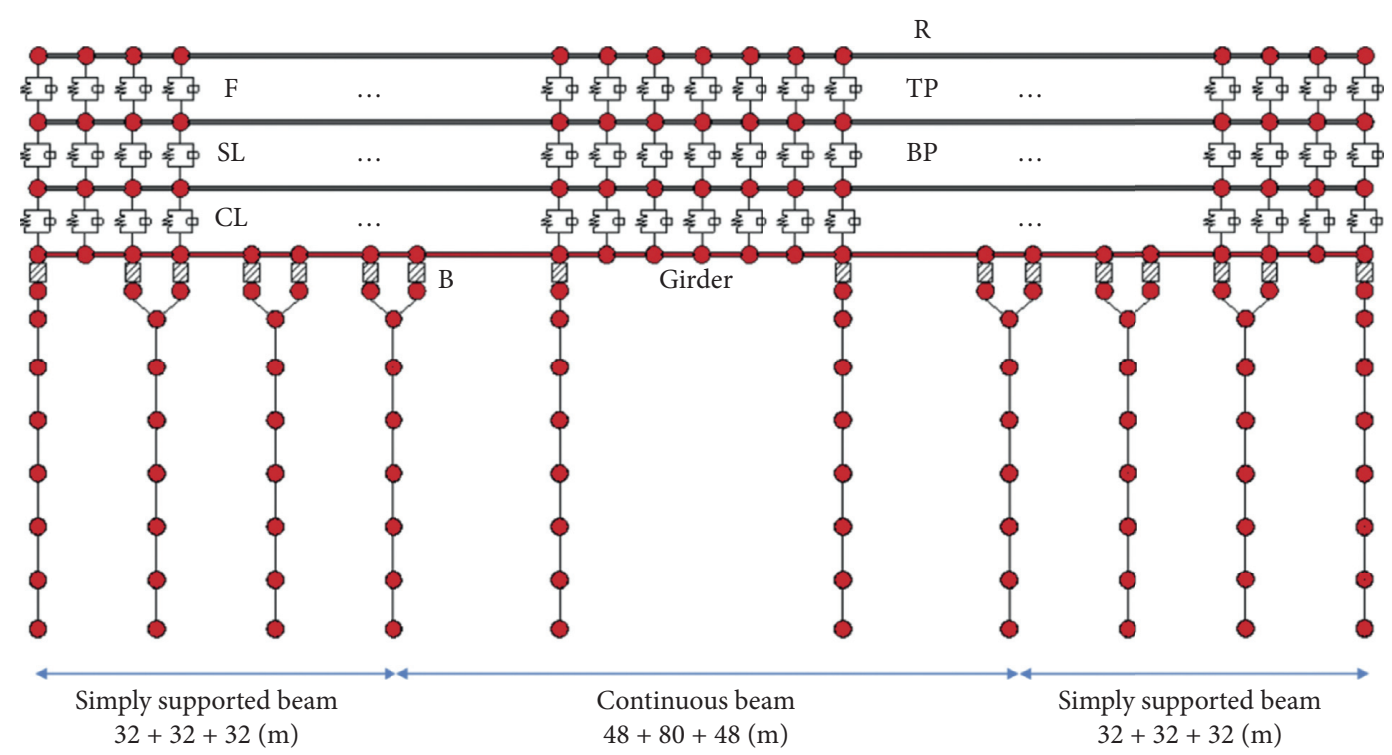

FIGURE 8: Elevation view of modeling scheme for HSRB prototype (R: rail, F: fasten, TP: track plate, BP: base plate, SL: slide layer, B: bearing, and CL: CA layer).

The connecting components in the upper strucutre (e.g., the CA layer and rail fasten) were unlikely damaged when the HSRB subjected to the earthquake excitations. Therefore, the change of irregularity in the rail was mainly ascribed to the result of the unrecoverable deformation of the lower structure (e.g., the HSRB piers). In this FE model, the rails and fastens have been modeled with the parameters obtained from the relevant research [39]. As there were no rails and fastens constructed on the testing HSRB specimen (while its scaled mass was considered), the comparison of acceleration, displacement, and strain time histories between experiments and calculations was used to validate this FE model. For example, Figure 9 shows the comparison of seismic behavior (acceleration, displacement, and strain) of Pier 1 between the experimental and FE model [37], respectively. It can be seen that the time histories were reasonably consistent, and the results were not very sensitive to the material properties used.

To be specific, the comparisons of maximum values (acceleration, displacement, and strains) between experimental and FE model results [37] are given in Tables 3 and 4. The results show that the maximum errors of acceleration and displacement in the side piers (Pier 1 and Pier 4) were around $10 \%$ to $12 \%$, while less than $10 \%$ of maximum error can be found in central piers (Pier 2 and Pier 3 ). This difference in maximum error between the side piers and central piers may be explained by the fact that the FE model considers the influence of the three simply supported girder spans at the end of the continuous girder bridge, while only one-span adjacent simply supported girder bridge was constructed for the experiment due to the working limits of shake tables. Therefore, the error of this FE model was acceptable and can be used for a more detailed study in the following section.

\section{Influence of Earthquake on the Rail Irregularity of Chinese HSRB}

4.1. Influence of Earthquake Intensity. To study the influence of the earthquake on the rail irregularity for the Chinese HSRB system, the change of PSD and displacement excitation sample after subjecting to different earthquake intensities were studied in this section. Moreover, to compare with other similar studies in China, the range of sampling rail wavelength in this research was selected from $2 \mathrm{~m}$ to $200 \mathrm{~m}$, and the speed of the train was at $350 \mathrm{~km} / \mathrm{h}$. The comparison of gauge and cross irregularity samples is illustrated in Figure 10. It can be clearly seen that the earthquake intensity does not influence the gauge and cross irregularities. Specifically, the displacement samples of these irregularities (Figure 10) are the same when the bridge with (PGA scale from $0.10 \mathrm{~g}$ to $0.50 \mathrm{~g}$ ) and without (W.O.) subjected to the earthquake excitations. This is because the seismic residual displacements of left and right rails in gauge and cross irregularities are the same after subjecting to the earthquake excitation. Therefore, there is no additional displacement produced by the earthquake for these irregularities, as $D_{I}=D_{L}-D_{R}=0$, where $D_{I}$ refers to the gauge or cross irregularity induced by the earthquake and $D_{L}$ and $D_{R}$ represent the residual displacement of left and right rails, respectively. Moreover, as the time-domain displacement sample is the same, the PSD of gauge and cross after the HSRB subjected to these earthquakes also have no changes. Therefore, it can be concluded that the existing expression of PSD for gauge and cross irregularities (without undergoes earthquake excitation) can still be used even after subjecting to the earthquake excitations.

The influence of earthquake intensity on the rail alignment irregularity is shown in Figure 11. It illustrates that this type of irregularity is affected obviously by the 


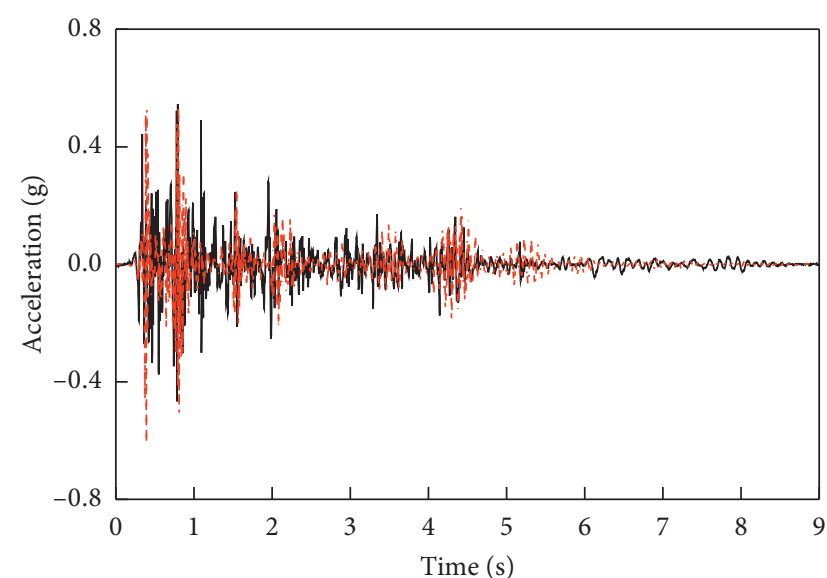

- Experimental results

- - - FE modelling results

(a)

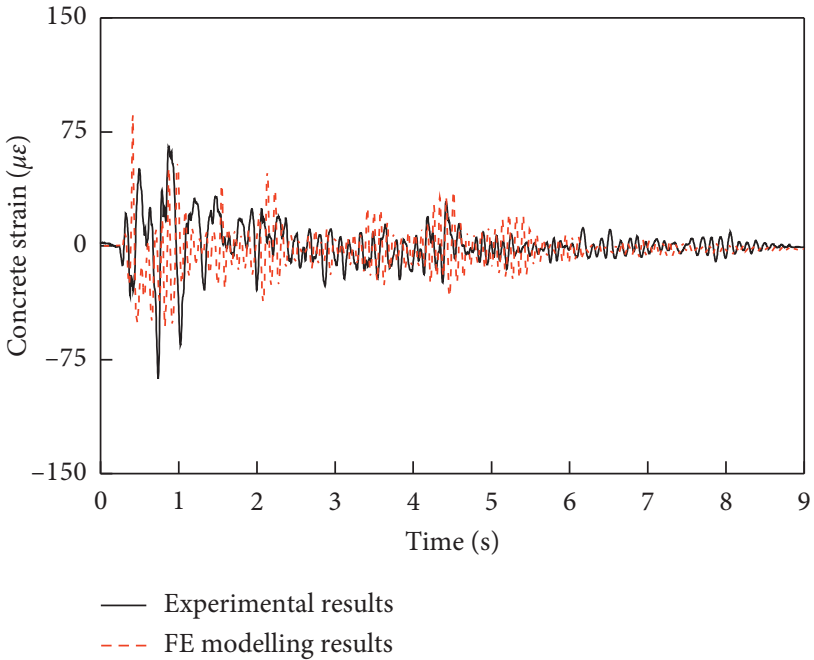

(c)

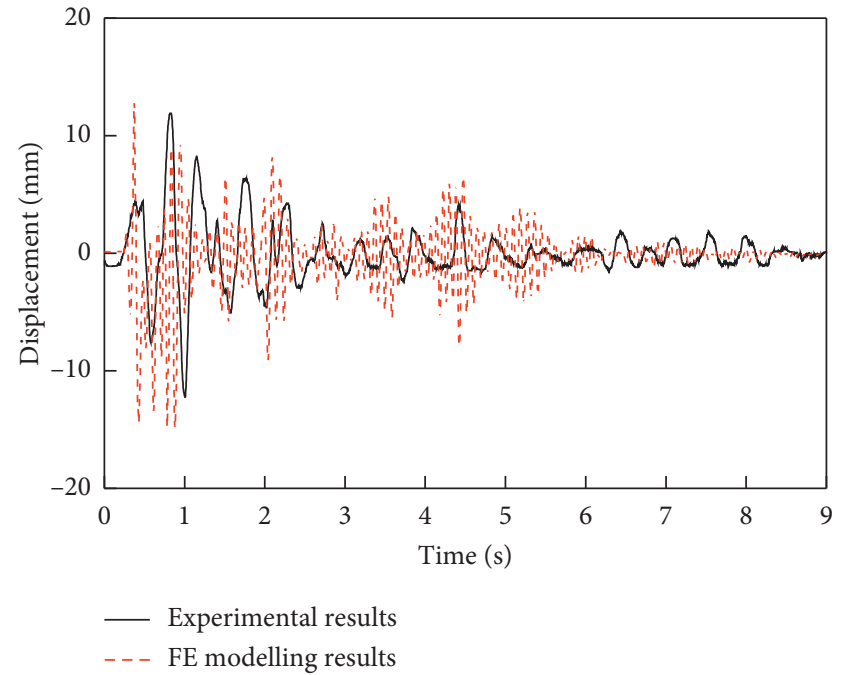

(b)

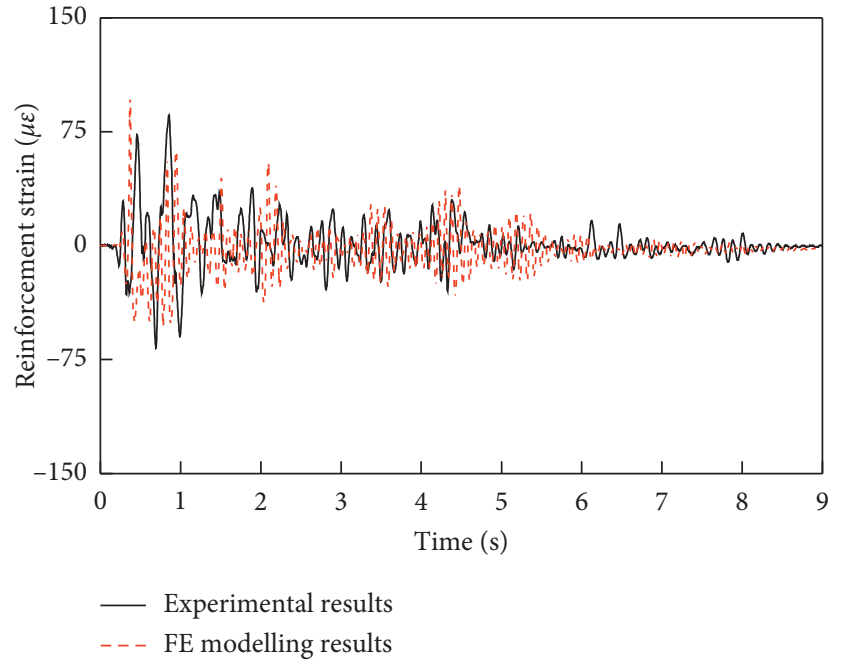

(d)

Figure 9: Comparison between testing and calculation results of Pier 1 for (a) acceleration, (b) displacement, (c) concrete strain, and (d) reinforcement strain.

TABle 3: Maximum absolute acceleration and displacement at each top of the pier for the experimental test and FE model.

\begin{tabular}{lcccc}
\hline Comparison & Pier number & Test & Calculation & Error (\%) \\
\hline & 1 & 0.59 & 0.62 & 0.55 \\
Maximum acceleration (g) & 2 & 0.59 & 0.48 & -6.78 \\
& 3 & 0.44 & 0.69 & 9.09 \\
\hline & 4 & 0.60 & 17.12 & 5.00 \\
Maximum displacement (mm) & 1 & 16.23 & 5.48 \\
& 2 & 25.21 & 26.79 & 9.57 \\
& 3 & 11.87 & 13.03 & 9.77 \\
\hline
\end{tabular}

earthquake intensity. To be specific, the original magnitude of alignment irregularity of the HSRB without subjecting to the earthquake (W.O.) is only about $2.3 \mathrm{~mm}$. It increases gradually with the increase of earthquake intensity, and eventually, around $45.3 \mathrm{~mm}$ can be found when the earthquake intensity increases to the PGA scale of $0.50 \mathrm{~g}$. The results can be ascribed to the fact that the damage of the HSRB system becomes more evident with the increase of earthquake intensity. Therefore, the residual displacement of rail after subjecting to the earthquake is increased, which resulted in an increasing rail alignment irregularity. The comparison of alignment PSD subjected to different 
TABLE 4: Maximum tensile strain of concrete and reinforcement bar at each bottom of the pier for the experimental test and FE model.

\begin{tabular}{|c|c|c|c|c|}
\hline Comparison & Pier number & Test & Calculation & Error $(\%)$ \\
\hline \multirow{4}{*}{ Maximum tensile strain concrete $(\mu \varepsilon)$} & 1 & 59.7 & 88.84 & 48.91 \\
\hline & 2 & 53.3 & 44.67 & -16.19 \\
\hline & 3 & 40.8 & 50.12 & 22.84 \\
\hline & 4 & 59.1 & 79.20 & 34.01 \\
\hline \multirow{4}{*}{ Maximum tensile strain reinforcement bar $(\mu \varepsilon)$} & 1 & 86.2 & 96.84 & 12.34 \\
\hline & 2 & 69.3 & 76.65 & 10.61 \\
\hline & 3 & 56.2 & 42.63 & -24.15 \\
\hline & 4 & 85.1 & 97.32 & 14.36 \\
\hline
\end{tabular}

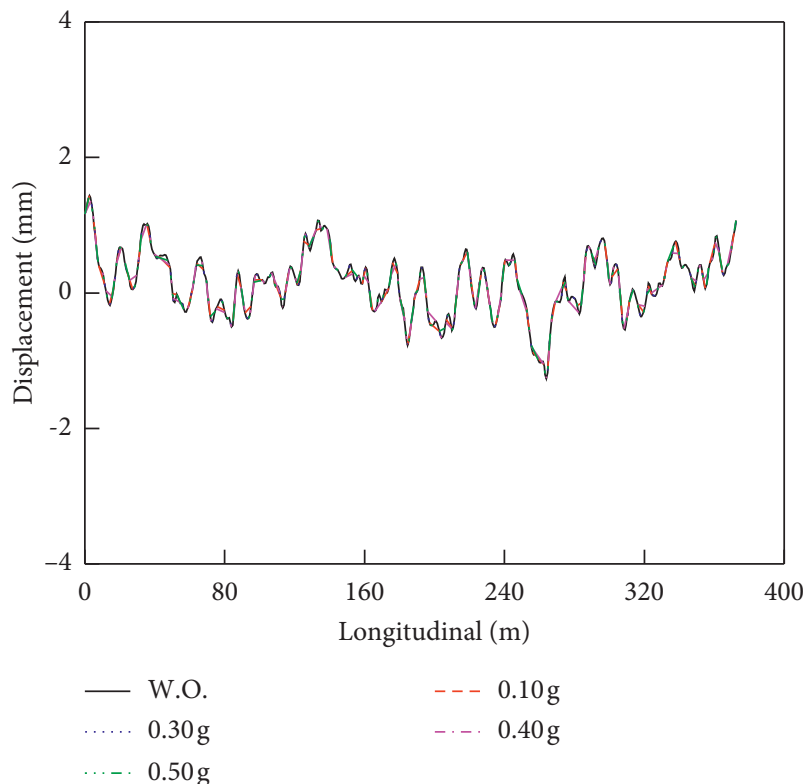

(a)

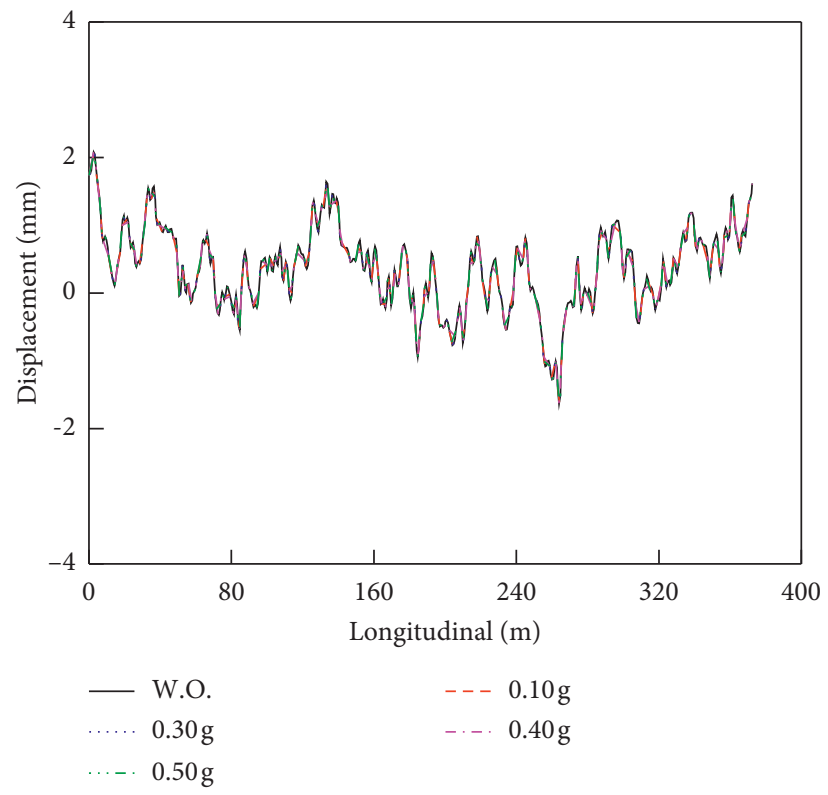

(b)

FIGURE 10: The comparison of displacement sample for (a) gauge and (b) cross irregularities.

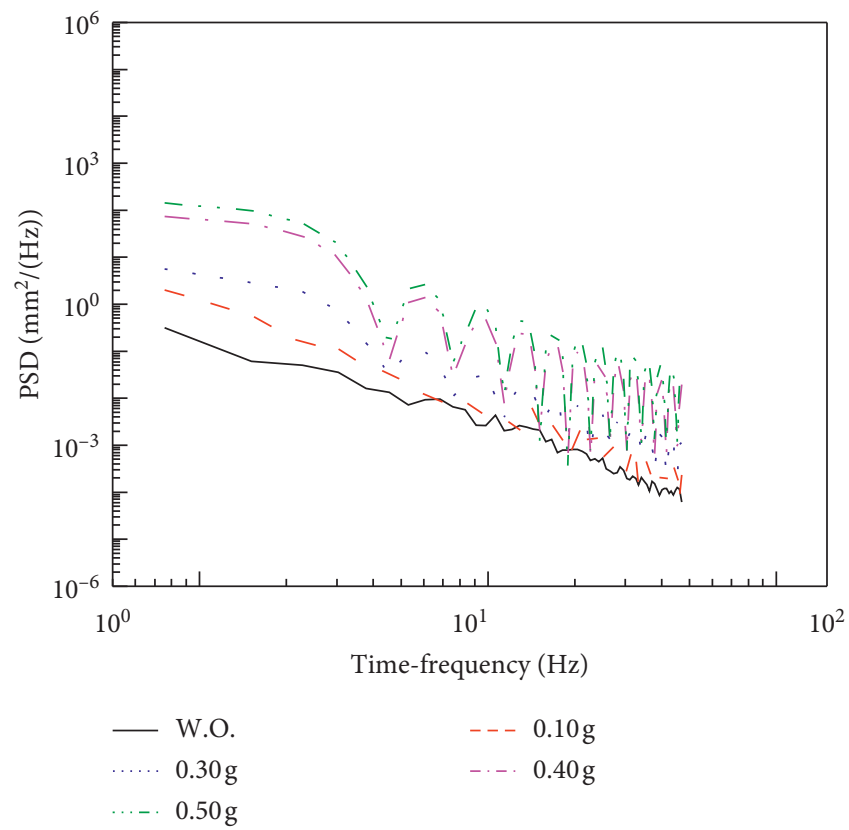

FIGURE 11: The comparison of alignment irregularity PSD. earthquake intensities shows that the rail alignment PSD changed significantly, and the original PSD (W.O.) is not suitable for more precise analysis after subjecting to the earthquakes. Therefore, a new form of expression of PSD after subjecting to different intensities of earthquake excitation should be developed for more detailed study. Figure 11 also illustrates that influences of the earthquake intensities on the earthquake-influenced PSDs under different intensities are mainly within the low-frequency domain, while relatively minor differences can be found in high frequency. The relationship between the frequency and wavelength is $f=v / \lambda$, where $v$ is the speed and $\lambda$ refers to the wavelength. Therefore, the results also indicate that for alignment irregularity, the long-wavelength sampling along the rail is easily affected by the earthquake.

Furthermore, since the vertical earthquake is not considered in the analysis, the influence of earthquake on the change of vertical irregularity (Figure 12) shows that the displacement sample is changed insignificantly with the increase of earthquake intensity. Compared to the alignment PSD (Figure 12), an inverse trend can be seen in vertical PSD (Figure 12(b)). To be specific, the PSD of vertical irregularity 


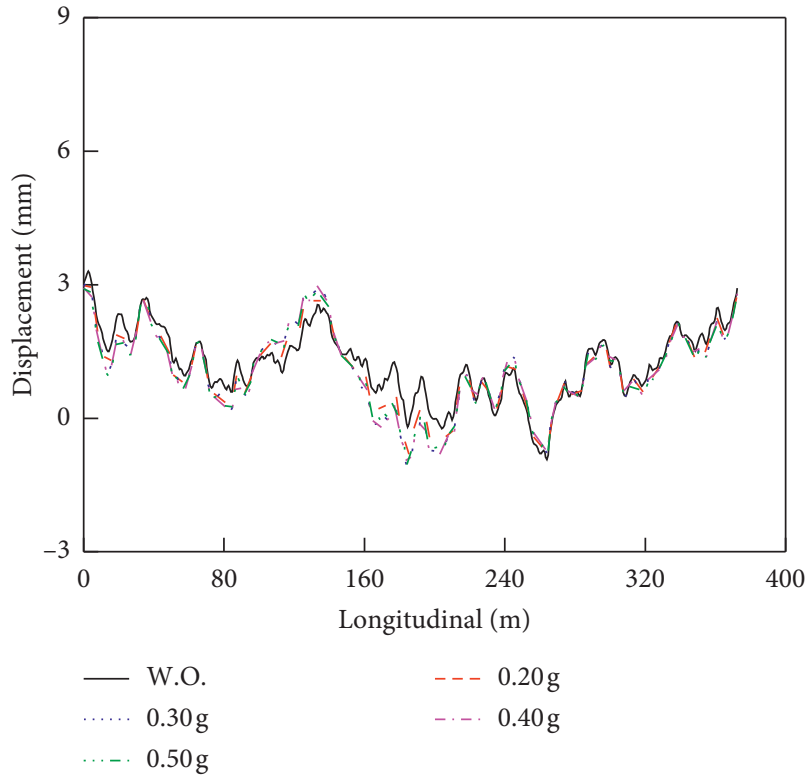

(a)

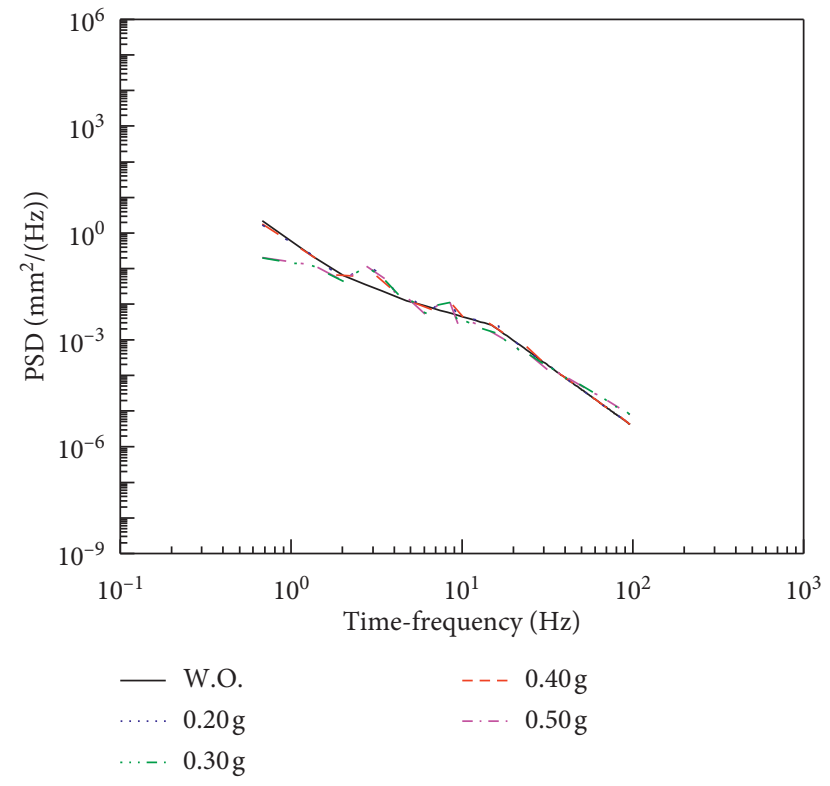

(b)

FIGURE 12: The comparison of vertical irregularity for (a) displacement sample and (b) PSD.

after subjecting to the earthquake is more significant than that of without earthquake excitation when the sampling is in the high-frequency (or short wavelength) domain. The results show that the PSD of vertical irregularity is affected differently by the earthquake intensity between high and low sampling frequencies. Moreover, this difference becomes apparent when subjected to violent excitations $(0.40 \mathrm{~g}$ and $0.50 \mathrm{~g}$ ). This can be explained that more obvious unrecoverable displacement in the vertical direction can be found in the rail when the bridge was subjected to more violent earthquake excitations.

4.2. Influence of Earthquake's Soil Sites. Bridges were usually constructed at different types of soil sites, and the velocity of earthquake wave spread in each soil site was correspondingly different. In this study, four typical types of earthquake ground motions were selected corresponding to different soil sites as excitations for the FE analysis, to investigate the influence of earthquake characteristics on the change of rail irregularity. The earthquakes were selected from the PEER Ground Motion Database (https://ngawest2.berkeley.edu/), and a comparison of the acceleration spectra for these earthquakes is shown in Figure 13. It can be seen that the characteristic periods of earthquake waves are decreased with the increase in velocity. The magnitudes of rail irregularities subjected to different earthquake excitation with the PGA of $0.50 \mathrm{~g}$ are given in Table 5. It shows that the rail displacement sample of alignment irregularity changed dramatically under different excitations of ground motions.

Specifically, in terms of earthquake velocities, the magnitude of the displacement sample decreased from around $78.4 \mathrm{~mm}$ (earthquake velocity below $150 \mathrm{~m} / \mathrm{s}$, soil site IV) to about $22.8 \mathrm{~mm}$ (earthquake velocity beyond $500 \mathrm{~m} / \mathrm{s}$, soil site I). Figure 14 also indicates that, compared

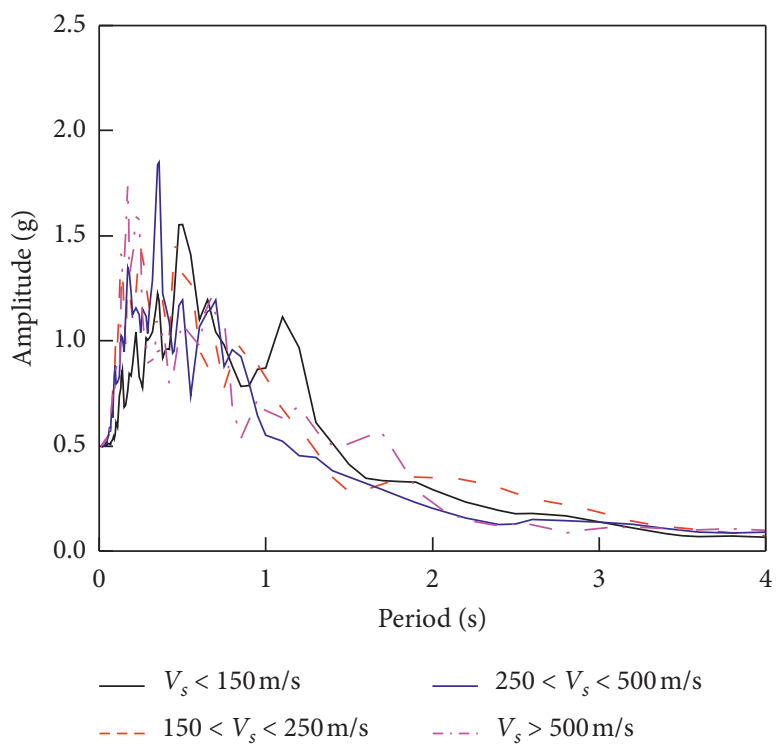

FIGURE 13: Scaled acceleration spectra for the selected ground motions in different soil sites.

to the bridge subjected to the high-velocity earthquake (soil site I), the PSD changed obviously when earthquake excitation with low velocity (soil site IV) is undergone. The results can be explained by the fact that the HSRB with multiple spans has a long characteristic period. Therefore, it is more vulnerable to the earthquake, which also has a long characteristic period (low velocity). Since earthquake velocity in soil sites II and III is similar, the magnitudes of rail irregularity after earthquakes in these two sites are similar. Figure 14 also indicates that the PSD after earthquakes in sites II and III is similar. 
TABLe 5: The maximum displacement of rail after subjecting to the earthquake excitation with different shear velocities (unit: mm).

\begin{tabular}{ccccc}
\hline PGA $(\mathrm{g})$ & Earthquake velocity $(\mathrm{m} / \mathrm{s})$ & Soil site & Characteristic period $(\mathrm{s})$ & Alignment irregularity $(\mathrm{mm})$ \\
\hline & $<150$ & IV & 0.5 & 78.4 \\
0.50 & $150-250$ & III & 0.46 & 38.8 \\
& $250-500$ & II & 0.36 & 45.3 \\
& $>500$ & I & 0.17 & 22.8 \\
\hline
\end{tabular}

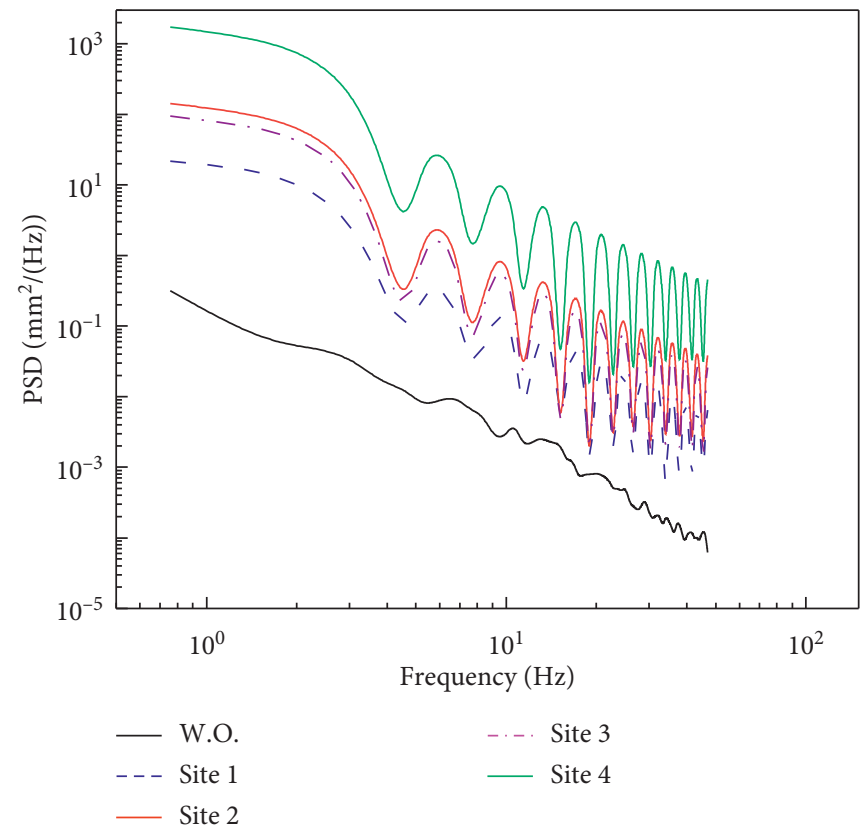

FIGURE 14: PSD comparisons of alignment irregularities under different soil sites.

Since the residual displacement of left and right rails is the same after earthquake excitation, no difference can be found in the PSD of gauge and cross irregularities. Therefore, the existing PSD (without subjected to the earthquakes) can still be used to express the gauge and cross irregularities, which is affected by different earthquake velocities.

Overall, the calculation results show that the soil site of earthquake affects the rail alignment irregularity significantly. Moreover, ground motion in the soft soil sites can cause more severe changes in the magnitude and PSD of the rail irregularity after the earthquake.

4.3. Influence of Earthquake Duration. To investigate the influences of the earthquake durations on the rail irregularities after the earthquake, four typical ground motions (GMs) corresponding to type II soil sites $\left(150<v_{s}<250 \mathrm{~m} / \mathrm{s}\right)$ were selected, and the scaled acceleration spectra with PGA of $0.5 \mathrm{~g}$ are demonstrated in Figure 15. The duration per earthquake wave varies from 13.25 to $47.34 \mathrm{~s}$. The magnitudes of rail irregularity subjected to ground motions with different durations are demonstrated in Table 6 . The results indicate that ground motions one and three have similar characteristic periods, while the magnitude of ground motion one is three times over that of GM 3 since the duration of ground motion one is almost four times over that of GM 3. Figure 16 also shows that the earthquake with

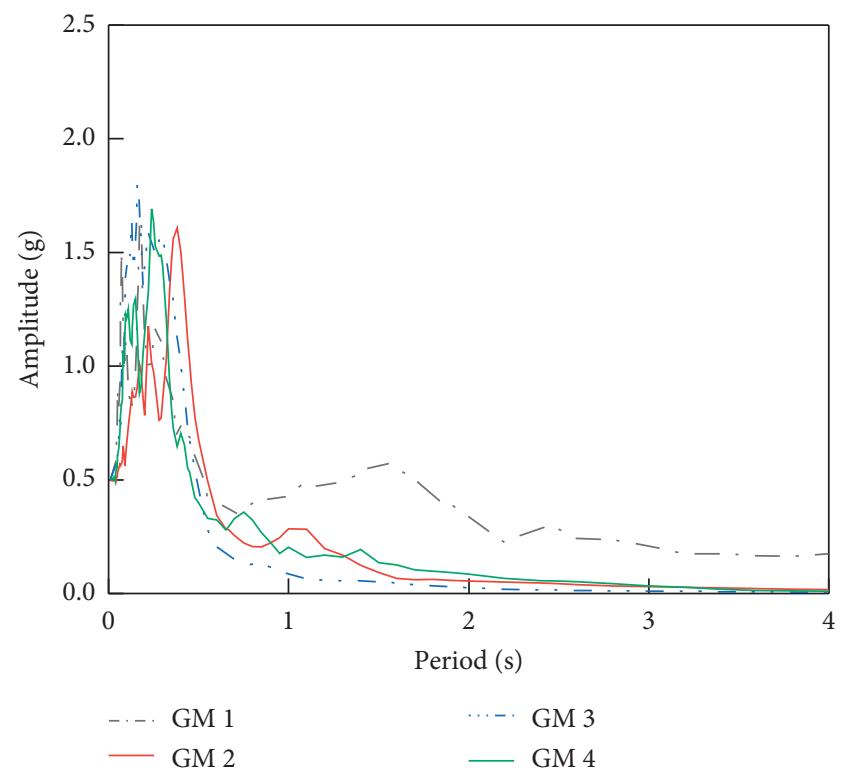

FIgURE 15: Scaled acceleration spectra for the selected ground motions with different durations.

the longest durations causes the most significant changes in the rail irregularity PSD. In general, when the characteristic periods are similar, the ground motion with a longer duration can result in lager magnitude of the rail irregularity. 
TABLE 6: Magnitudes of rail irregularity under different earthquake durations.

\begin{tabular}{cccc}
\hline PGA (g) & Duration $(\mathrm{s})$ & Characteristic period $(\mathrm{s})$ & Alignment irregularity $(\mathrm{mm})$ \\
\hline \multirow{3}{*}{0.50} & 47.34 & 0.18 & 61.96 \\
& 33.46 & 0.38 & 22.91 \\
& 13.25 & 0.16 & 19.61 \\
& 27.91 & 0.24 & 23.17 \\
\hline
\end{tabular}

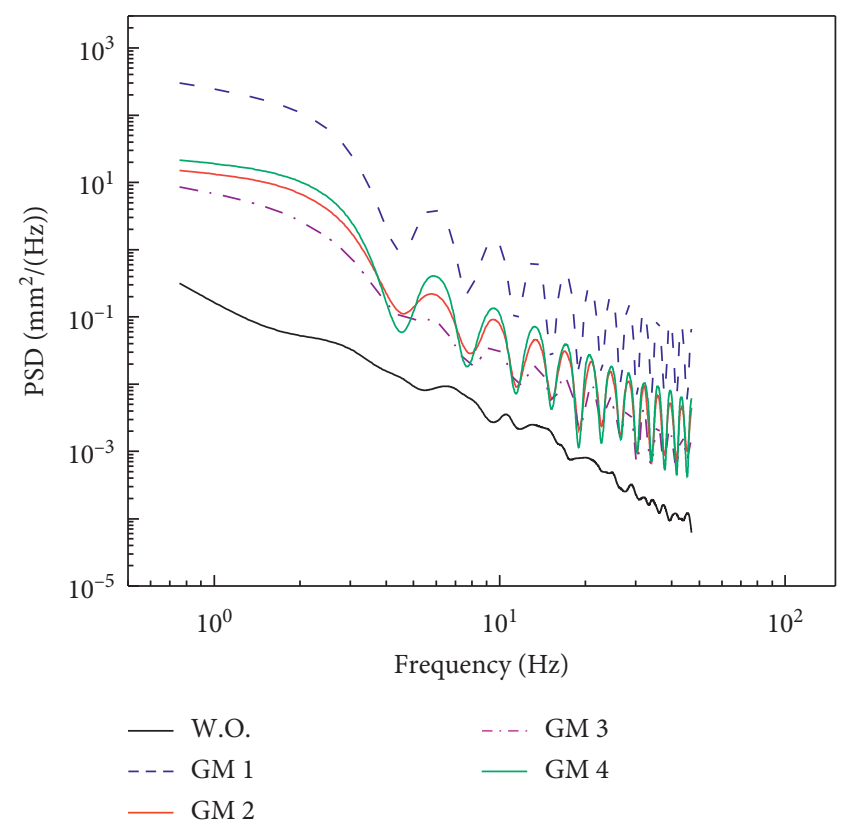

FIGURE 16: PSD of alignment irregularities under different earthquake durations.

However, the results of the rail irregularity after ground motions two and four demonstrated that when differences of characteristic periods become larger, the ground motion with longer duration may even have smaller magnitude of rail irregularity. Figure 16 also shows that PSDs of rail irregularity after ground motions two and four have similar results.

\section{Summary and Conclusions}

The differences in rail irregularity (i.e., time-domain displacement sample and power spectrum density (PSD) of rail irregularity) between different countries (i.e., America, Germany, and China) were studied in detail in this paper. Moreover, to figure out the influence of earthquake (different earthquake intensities and velocities) on the change of irregularity, one specific HSRB with ballastless track in China was selected for parameter analysis. The finite element (FE) model of this HSRB was established and validated by the shaking table test of a 1/12-scaled HSRB experimental specimen. To be specific, the following conclusions can be drawn from this study:

(1) The PSD of rail irregularity in China is smaller compared to that of Germany when the sampling space-frequency is within a specific range. Specifically, the space-frequency is below $0.25(1 / \mathrm{m})$ for alignment irregularity and ranges from around 0.014 to $0.275(1 / \mathrm{m})$ for cross irregularity. Interestingly, the vertical irregularity PSD in China is smaller than that of Germany for all range of space-frequency, while an inverse trend can be seen in the gauge PSD. Moreover, because the track is not used for a highspeed train, the PSDs of America is the largest one for all types of irregularities.

(2) An efficient method to convert the PSD to a timedomain displacement sample is introduced for better studying the excitation of rail irregularity to the train. It can be seen from the results that the displacement sample of rail irregularities in Chinese HSRB is the smallest one compared to that of Germany (medium) and America (most significant).

(3) A finite element (FE) model had been established for a more detailed study, and its correctness was validated by a shaking table test of 1/12-scaled experimental specimen. The methods of modeling and experiment process can be applied or improved for another similar research.

(4) Calculation results show that the earthquake intensity has obvious effects on the rail alignment irregularity. In general, the magnitude of rail irregularity after earthquake increases as the PGA of ground motion increases. The magnitude of PSD of rail irregularity after the earthquake also increases as the PGA of ground motion increases.

(5) The PSD of alignment experienced the most significant change when the HSRB was subjected to the earthquake in soil site IV. This can be ascribed to the fact that the characteristic period of earthquake increased with the decrease of earthquake velocity, and the seismic performance of HSRB is apparent when subjected to the long characteristic period of earthquake excitation.

(6) When characteristic periods of ground motions are similar, the ground motion with longer duration can result in lager change in the PSD of rail irregularity. However, when the characteristic differs, the effect of duration cannot be simply addressed.

\section{Data Availability}

All data generated or analyzed during this study are included in the published article.

\section{Conflicts of Interest}

The authors declare that they have no conflicts of interest. 


\section{Acknowledgments}

This research was financially supported by the National Natural Science Foundation of China (51708630).

\section{References}

[1] C. Chang, L. Liang, H. Zhaoling, W. Kaiyun, and Z. Wanming, "High-speed train-track-bridge dynamic interaction considering wheel-rail contact nonlinearity due to wheel hollow wear," Shock and Vibration, vol. 2019, Article ID 5874678, 18 pages, 2019.

[2] T. Xin, P. Wang, and Y. Ding, "Effect of long-wavelength track irregularities on vehicle dynamic responses," Shock and Vibration, vol. 2019, Article ID 4178065, 11 pages, 2019.

[3] W. M. Zhai and H. True, "Vehicle-track dynamics on a ramp and on the bridge: simulation and measurements," Vehicle System Dynamics, vol. 33, no. sup1, pp. 604-615, 1999.

[4] Z.-w. Yu, J.-f. Mao, F.-q. Guo, and W. Guo, "Non-stationary random vibration analysis of a $3 \mathrm{D}$ train-bridge system using the probability density evolution method," Journal of Sound and Vibration, vol. 366, pp. 173-189, 2016.

[5] M. Bayat, H. R. Ahmadi, and N. Mahdavi, "Application of power spectral density function for damage diagnosis of bridge piers," Structural Engineering and Mechanics, vol. 71, no. 1, pp. 57-63, 2019.

[6] K. Youcef, T. Sabiha, D. El Mostafa, D. Ali, and M. Bachir, "Dynamic analysis of train-bridge system and riding comfort of trains with rail irregularities," Journal of Mechanical Science and Technology, vol. 27, no. 4, pp. 951-962, 2013.

[7] Z. Jin, B. Huang, R. Juanjuan, and P. Shiling, "Reduction of vehicle-induced vibration of railway bridges due to distribution of axle loads through track," Shock and Vibration, vol. 2018, Article ID 2431980, 14 pages, 2018.

[8] S. L. Grassie, M. J. Saxon, and J. D. Smith, "Measurement of longitudinal rail irregularities and criteria for acceptable grinding," Journal of Sound and Vibration, vol. 227, no. 5, pp. 949-964, 1999.

[9] T. Luck, E. Lohneif, B. Eissfeller, and P. Memke, "Track irregularity measurement using an INS-GPS integration technique," in Proceedings of the Seventh International Conference on Computers in Railways. Computers in Railways VII, WIT Press, Bologna, Italy, September 2000.

[10] X. Q. Du, Z. H. Yao, and Z. C. Chen, "Wavelet denoising of the horizontal vibration signal for identification of the guide rail irregularity in elevator," Key Engineering Materials, vol. 353-358, pp. 2794-2797.

[11] Y. Q. Sun, C. Cole, M. McClanachan, A. Wilson, and S. Kaewunruen, "Rail short-wavelength irregularity identification based on wheel-rail impact response measurements and simulations," in Proceedings of the International Heavy Haul Conference, Shanghai, China, June 2009.

[12] Q. Chen, X. Niu, Q. Zhang, and Y. Cheng, "Railway track irregularity measuring by GNSS/INS integration," Navigation, vol. 62, no. 1, pp. 83-93, 2015.

[13] J. Kawasaki and K. Youcef-Toumi, "Estimation of rail irregularities," in Proceedings of the 2002 American Control Conference (IEEE Cat. No.CH37301), Anchorage, AK, USA, IEEE, May 2002.

[14] A. Haigermoser, B. Luber, J. Rauh, and G. Gräfe, "Road and track irregularities: measurement, assessment and simulation," Vehicle System Dynamics, vol. 53, no. 7, pp. 878-957, 2015.
[15] D. Zenunovic, M. Topalovic, and R. Folic, "Identification of modal parameters of bridges using ambient vibration measurements," Shock and Vibration, vol. 2015, Article ID 957841, 21 pages, 2015.

[16] M. Bayat and I. Pakar, "On the approximate analytical solution to non-linear oscillation systems," Shock and Vibration, vol. 20, no. 1, pp. 43-52, Article ID 549213, 2013.

[17] C. Kang, S. Schneider, M. Wenner, and S. Marx, "Development of design and construction of high-speed railway bridges in Germany," Engineering Structures, vol. 163, pp. 184-196, 2018.

[18] M. Su, G. Dai, S. Marx, W. Liu, and S. Zhang, "A brief review of developments and challenges for high-speed rail bridges in China and Germany," Structural Engineering International, vol. 29, no. 1, pp. 160-166, 2019.

[19] L. Jiang, Y. Zhang, Y. Feng, W. Zhou, and Z. Tan, “Dynamic response analysis of a simply supported double-beam system under successive moving loads," Applied Sciences, vol. 9, no. 10, p. 2162, 2019.

[20] Z. Lai, L. Jiang, and W. Zhou, "An analytical study on dynamic response of multiple simply supported beam system subjected to moving loads," Shock and Vibration, vol. 2018, Article ID 2149251, 14 pages, 2018.

[21] M. Gae, J. Xiong, and J. Zhan, "Sensitive wavelength of track irregularity and its influence on dynamic responses of trainbridge system in high-speed railway," in Proceedings of the 8th International Conference on Structural Dynamics, EURODYN 2011, Leuven, Belgium, July 2011.

[22] X. Yang, S. Gu, S. Zhou, J. Yang, Y. Zhou, and S. Lian, "Effect of track irregularity on the dynamic response of a slab track under a high-speed train based on the composite track element method," Applied Acoustics, vol. 99, pp. 72-84, 2015.

[23] M. H. Kagarnovin, D. Younesian, D. Thompson, and C. Jones, "Ride comfort of high-speed trains travelling over railway bridges," Vehicle System Dynamics, vol. 43, no. 3, pp. 173-197, 2005.

[24] H. Xia and N. Zhang, "Dynamic analysis of railway bridge under high-speed trains," Computers \& Structures, vol. 83, no. 23-24, pp. 1891-1901, 2005.

[25] B. Biondi, G. Muscolino, and A. Sofi, "Dynamic analysis of railway bridges with random vertical rail irregularities," in Proceedings of the Third International Conference on Bridge Maintenance, Safety and Management, Porto, Portugal, CRC Press, July 2006.

[26] X. Q. Wang and X. Zhang, "Rail irregularity power spectrum of high-speed railways," Applied Mechanics and Materials, vol. 373-375, pp. 99-103, 2013.

[27] J. Y. Li, L. Y. Liu, and D. H. Kou, "Wu Guang high-speed rail track irregularity power spectrum analysis," Applied Mechanics and Materials, vol. 638-640, pp. 1224-1228, 2014.

[28] A. A. Najafabadi, F. Daneshjoo, and H. R. Ahmadi, "Multiple damage detection in complex bridges based on strain energy extracted from single point measurement," Frontiers of Structural and Civil Engineering, vol. 14, no. 3, pp. 722-730, 2020.

[29] J. Choi, J. Chung, and S. Kim, "Experimental study on trackbridge interactions for direct fixation track on long-span railway bridge," Shock and Vibration, vol. 2019, Article ID 1903752, 9 pages, 2019.

[30] H. R. Ahmadi, F. Daneshjoo, and N. Khaji, "New damage indices and algorithm based on square time-frequency distribution for damage detection in concrete piers of railroad bridges," Structural Control and Health Monitoring, vol. 22, no. 1, pp. 91-106, 2015. 
[31] H. R. Ahmadi and D. Anvari, "New damage index based on least squares distance for damage diagnosis in steel girder of bridge's deck," Structural Control and Health Monitoring, vol. 25 , no. 10 , p. e2232, 2018.

[32] V. Garg, Dynamics of Railway Vehicle Systems, Elsevier, Amsterdam, Netherlands, 2012.

[33] National Railway Administration, High Speed Railway Design Code (China), China Railway Press, Beijing, China, 2014.

[34] M. Naeimi, J. A. Zakeri, M. Esmaeili, and M. Shadfar, "Influence of uneven rail irregularities on the dynamic response of the railway track using a three-dimensional model of the vehicle-track system," Vehicle System Dynamics, vol. 53, no. 1, pp. 88-111, 2015.

[35] W. Zhai and C. Guo, "Numerical simulation of the stochastic process of railway track irregularities," Journal of Southwest Jiaotong University, vol. 34, no. 2, pp. 138-142, 1999.

[36] W. M. Zhai, Vehicle-Track Coupled Dynamics, Springer, Singapore, 2015.

[37] X. Kang, L. Jiang, Y. Bai, and C. C. Caprani, "Seismic damage evaluation of high-speed railway bridge components under different intensities of earthquake excitations," Engineering Structures, vol. 152, pp. 116-128, 2017.

[38] B. Wei, T. Yang, L. Jiang, and X. He, "Effects of uncertain characteristic periods of ground motions on seismic vulnerabilities of a continuous track-bridge system of high-speed railway," Bulletin of Earthquake Engineering, vol. 16, no. 9, pp. 3739-3769, 2018.

[39] D. A. Aguirre, C. A. Gaviria, and L. A. Montejo, "Waveletbased damage detection in reinforced concrete structures subjected to seismic excitations," Journal of Earthquake Engineering, vol. 17, no. 8, pp. 1103-1125, 2013. 